\title{
Direitos humanos, educação e interculturalidade: as tensões entre igualdade e diferença*
}

\author{
Vera Maria Candau \\ Pontifícia Universidade Católica do Rio de Janeiro, Departamento de Educação
}

No mundo atual, a consciência de que estamos vivendo mudanças profundas que ainda não somos capazes de compreender adequadamente é cada vez mais aguda. Para muitos intelectuais e atores sociais, não estamos simplesmente vivendo uma época de mudanças significativas e aceleradas, e sim uma mudança de época. Essa realidade provoca perplexidade e suscita uma ampla produção científica e cultural, assim como um intenso e acalorado debate. Muitas são as leituras da crise global de paradigma que estamos atravessando. Cientistas políticos, sociólogos, economistas, filósofos, teólogos, psicólogos, informatas, literatos, físicos, artistas, diferentes produtores intelectuais e culturais se dedicam a analisar essa problemática.

\footnotetext{
* Este texto é uma versão revisada da comunicação apresentada no painel sobre o tema "Direitos humanos numa perspectiva multicultural e pluralista", no Congresso Interamericano de Diretos Humanos realizado em Brasília, em agosto de 2006, promovido pela Secretaria Especial de Direitos Humanos e pelo Ministério de Educação, com o apoio da Organização das Nações Unidas para a Educação, a Ciência e a Cultura (UNESCO).
}

Neste contexto, extremamente vivo e plural de discussão e busca, algumas questões podem ser identificadas como ocupando uma posição central nos debates, sendo expressão de matrizes teóricas e político-sociais diferenciadas. Entre elas podemos citar a problemática da igualdade e dos direitos humanos, em um mundo marcado por uma globalização neoliberal excludente, e as questões da diferença e do multiculturalismo, em tempos de uma mundialização ${ }^{1}$ com pretensões monoculturais.

Uma expressão dessa problemática pode ser evidenciada pela natureza do recentemente publicado Relatório do Desenvolvimento Humano 2004, do Programa das Nações Unidas para o Desenvolvimento

\footnotetext{
${ }^{1}$ Renato Ortiz (1994) distingue globalização de mundiali-
} zação, concebendo a primeira como referida fundamentalmente à economia, "à produção, distribuição e consumo de bens e de serviços, organizados a partir de uma estratégia mundial e voltada para um mercado mundial" (p. 16) e a segunda como um "fenômeno social total que permeia o conjunto das manifestações culturais" (p. 30). 
(PNUD), intitulado Liberdade cultural num mundo diversificado, que associa explicitamente - pela primeira vez nos relatórios anuais publicados - as questões relativas ao desenvolvimento às culturais:

O que é novo, hoje, é a ascensão de políticas de identidade. Em contextos muito diferentes e de modos muito diversos - desde os povos indígenas da América Latina às minorias religiosas na Ásia do Sul e às minorias étnicas nos Bálcãs e em África, até os imigrantes na Europa Ocidental - as pessoas estão se mobilizando de novo em torno de velhas injustiças segundo linhas étnicas, religiosas, raciais e culturais, exigindo que sua identidade seja reconhecida, apreciada e aceite pela sociedade mais ampla. Sofrendo de discriminação e marginalização em relação a oportunidades sociais, econômicas e políticas, também exigem justiça social. (PNUD, 2004, p. 1)

Em todo o mundo as pessoas são mais afirmativas para exigir respeito pela sua identidade cultural. Muitas vezes, o que exigem é justiça social e mais voz política. Mas não é tudo. Também exigem reconhecimento e respeito... E importam-se em saber se eles e os filhos viverão em uma sociedade diversificada ou numa sociedade em que se espera que todas as pessoas se conformem com uma única cultura dominante. (p. 22)

A relação entre questões relativas a justiça, redistribuição, superação das desigualdades e democratização de oportunidades e as referidas ao reconhecimento de diferentes grupos culturais se faz cada vez mais estreita. Nesse sentido, a problemática dos direitos humanos, muitas vezes entendidos como direitos exclusivamente individuais e fundamentalmente civis e políticos, amplia-se e, cada vez mais, afirmase a importância dos direitos coletivos, culturais e ambientais.

Será que estamos vivendo hoje um deslocamento de ênfase? Alguns autores talvez vão mais longe, chegando a afirmar que, nessa busca ou nessa crise de paradigma que estamos vivendo na sociedade atual, também a questão dos direitos humanos fica de alguma forma em questão e precisa ser ressignificada.
Certamente todos estamos de acordo em afirmar que os direitos humanos são uma construção da modernidade e que estão profundamente impregnados com os processos, os valores, as afirmações que a modernidade propôs/propõe, legou-nos e continua instigando-nos a realizar. Vivemos imersos no seu clima político-ideológico e cultural. E, no entanto, para muitos autores essa construção está em crise no novo contexto cultural, social e econômico, marcado pela globalização, pelo impacto das novas tecnologias, pela construção de novas subjetividades e mentalidades, por esse mundo complexo que muitos autores chamam - por mais ambíguo que este termo seja - pósmodernidade.

Um elemento que me parece fundamental na questão é essa tensão, presente hoje no debate público e nas relações internacionais, entre igualdade e diferença. De maneira um pouco simplificada, é possível afirmar que toda a matriz da modernidade enfatizou a questão da igualdade. A igualdade de todos os seres humanos, independentemente das origens raciais, da nacionalidade, das opções sexuais, enfim, a igualdade é uma chave para entender toda a luta da modernidade pelos direitos humanos.

No entanto, parece que hoje o centro de interesse se deslocou. Quando digo que houve um deslocamento, não estou querendo dizer que se nega a igualdade, mas que se coloca muito mais em evidência o tema da diferença.

O professor Antonio Flavio Pierucci, no seu instigante livro Ciladas das diferenças (1999), sintetiza assim essa tensão:

Somos todos iguais ou somos todos diferentes? Queremos ser iguais ou queremos ser diferentes? Houve um tempo que a resposta se abrigava segura de si no primeiro termo da disjuntiva. Já faz um quarto de século, porém, que a resposta se deslocou. A começar da segunda metade dos anos 70, passamos a nos ver envoltos numa atmosfera cultural e ideológica inteiramente nova, na qual parece generalizar-se, em ritmo acelerado e perturbador, a consciência de que nós, os humanos, somos diferentes de fato [...], mas somos também diferentes de direito. É o chamado "direito à diferença", o 
direito à diferença cultural, o direito de ser, sendo diferente.

The right to be different!, como se diz em inglês, o direito à diferença. Não queremos mais a igualdade, parece. Ou a queremos menos, motiva-nos muito mais, em nossa conduta, em nossas expectativas de futuro e projetos de vida compartilhada, o direito de sermos pessoal e coletivamente diferentes uns dos outros. (Pierucci, 1999, p. 7)

O autor parece colocar a questão em termos alternativos: somos iguais ou somos diferentes? Sua tese é a de que até recentemente nossas lutas tinham como referência fundamental a afirmação da igualdade. $\mathrm{O}$ direito à diferença não tinha ainda aparecido com a força que tem hoje. No entanto, atualmente a questão da diferença assume importância especial e transforma-se num direito, não só o direito dos diferentes a serem iguais, mas o direito de afirmar a diferença. Pessoalmente, inclino-me a defender que certamente há uma mudança de ênfase e uma questão de articulação. Não se trata de afirmar um pólo e negar o outro, mas de articulá-los de tal modo que um nos remeta ao outro.

Partindo dessa questão básica, que vai orientar estas reflexões, considero fundamental que nos perguntemos pela relevância dos direitos humanos no contexto que estamos vivendo.

\section{Direitos humanos hoje: um discurso relevante?}

Assinalarei alguns aspectos que me parecem importantes para a nossa reflexão. O primeiro diz respeito à ambivalência em relação à afirmação e, ao mesmo tempo, à negação dos direitos. Por um lado, tanto no plano internacional quanto no plano nacional, existe um discurso reiterativo que afirma fortemente a importância dos direitos humanos. No entanto, as violações multiplicam-se. No plano internacional é possível identificar inclusive um retrocesso grande, por exemplo, em relação a direitos que pareciam profundamente assimilados pela humanidade, como o combate à tortura em qualquer circunstância. Direitos fundamentais que pareciam plenamente assegurados na mentalidade e nas políticas internacionais assumidas são negados, desprezados e "esquecidos".

Também no nosso país as violações se multiplicam. No entanto, é necessário reconhecer, tem sido feito um esforço sistemático orientado à defesa e proteção dos direitos fundamentais, tanto pelo governo como por organizações da sociedade civil, pelo menos nos últimos anos.

Outro elemento importante da problemática atual dos direitos humanos diz respeito à relação entre indivisibilidade e exigibilidade. A doutrina dos direitos humanos que se desenvolveu principalmente a partir da Conferência de Viena (1993) colocou grande ênfase na idéia da indivisibilidade dos direitos das diferentes gerações - civis, políticos, econômicos, sociais e culturais. No entanto, a exigibilidade desses direitos, imprescindível para que a indivisibilidade não seja meramente retórica, ainda é muito frágil, principalmente no que diz respeito aos direitos sociais, econômicos e culturais, o que provoca nos diferentes grupos sociais descrédito e indiferença para com a proclamação de direitos que, como se afirma na linguagem comum, "não saem do papel" ou somente valem para algumas pessoas e classes sociais. Considero essa tensão entre indivisibilidade e exigibilidade muito importante no momento atual.

Um terceiro elemento da problemática, ao qual já nos referimos e que consideramos que ocupa lugar central, é a tensão entre universal e particular. Desde a Declaração Universal, os direitos humanos são apresentados, como o próprio nome diz, como universais. No entanto, a questão do universal e do particular, ou do universal e do relativo, suscitou uma discussão particularmente forte na Conferência de Viena. E, hoje em dia, vários grupos em diferentes países questionam a universalidade dos direitos tal como foi construída, considerando-a uma expressão do Ocidente e da tradição européia. Partindo dessa perspectiva, é possível reconhecer as diferenças culturais, os diversos modos de situar-se diante da vida, dos valores, as várias lógicas de produção de conhecimento etc.? É possível construir uma articulação entre o universal e o particular, o universal e o relativo? 
Diante dessa problemática, acredito, como o sociólogo Boaventura Sousa Santos, professor da Universidade de Coimbra, que é necessária uma ressignificação dos direitos humanos na contemporaneidade. Sua tese é de que,

\section{[...] enquanto forem concebidos como direitos humanos universais em abstrato, os Direitos Humanos tenderão a operar como um localismo globalizado, e portanto como uma forma de globalização hegemônica. Para poderem ope- rar como forma de cosmopolitismo insurgente, como glo- balização contra-hegemônica, os Direitos Humanos têm de ser reconceitualizados como interculturais. (Santos, 2006, p. $441-442)^{2}$}

Para Santos, a construção dos direitos humanos foi feita dentro da perspectiva do "localismo globalizado". E essa era a matriz hegemônica própria da modernidade, claramente presente no expansionismo europeu, portador da "civilização" e das "luzes". É essa a óptica que tem predominado até hoje, com diferentes versões.

No entanto, o que ele chama de cosmopolitismo insurgente e subalterno é um dos processos que caracterizam a globalização que nasce de baixo para cima. Essa globalização surge dos grupos locais, das organizações da sociedade civil, dos temas que nascem verdadeiramente das inquietudes dos diferentes atores sociais.

${ }^{2} \mathrm{O}$ autor distingue quatro formas de globalização: localismo globalizado - processo pelo qual determinada realidade local é globalizada com sucesso; globalismo globalizado - impacto nas condições locais das práticas transnacionais; cosmopolitismo insurgente e subalterno - resistência organizada transnacionalmente contra os localismos globalizados e os globalismos localizados; e o patrimônio comum da humanidade - emergência das lutas transnacionais por valores ou recursos que são tão globais como o próprio planeta. Ele caracteriza as duas primeiras como globalização hegemônica, de cima para baixo; as duas últimas, como globalização contra-hegemônica ou a partir de baixo (Santos, 2006, p. 417-421).
Nessa perspectiva, segundo o autor (Santos, 2006, p. 445-447), para que os direitos humanos possam verdadeiramente ser ressignificados hoje, numa perspectiva que não nega as suas raízes, não nega a sua história, mas quer trazê-los para a problemática de hoje, eles terão que passar por um processo de reconceitualização. Essa passagem supõe algumas premissas que ele enumera da seguinte maneira:

1. A superação do debate entre o universalismo e o relativismo cultural. $\mathrm{O}$ que se quer dizer com isso? Afirmar que todas as culturas ou grupos culturais têm valores e idéias, elementos fundamentais que aspiram a comunicar a outros e universalizar, mas o universalismo é incorreto, enquanto uma única cultura predomine e queira se impor a todos. No outro pólo está o relativismo cultural, que afirma que todas as culturas são relativas, nenhuma é absoluta, nenhuma é completa, mas é necessário propor diálogos interculturais sobre preocupações convergentes, ainda que expressas a partir de diversos universos culturais. Somente assim seremos capazes de construir algo juntos, um projeto comum. É necessário negar tanto o universalismo quanto o relativismo absolutos.

2. Todas as culturas possuem concepções da dignidade humana. Nem todos os grupos culturais conhecem ou usam a expressão direitos humanos, mas isso não quer dizer que não tenham uma idéia de dignidade humana, de vida digna, de querer uma vida melhor para os seus habitantes ou para seus integrantes. Temos de ter sensibilidade para descobrir em cada universo sociocultural essa idéia de dignidade humana que traduzimos como direitos humanos.

3. Todas as culturas são incompletas e problemáticas nas suas concepções de dignidade humana. Afirmar que nenhuma cultura é completa, que nenhuma dá conta de toda a riqueza do humano, leva-nos a, muito mais do que trabalhar com a idéia de uma cultura verdadeira e única, que tem de ser universalizada, desen- 
volver a sensibilidade para com a idéia da incompletude de todas as culturas e, portanto, da necessidade da interação entre elas. Nenhuma cultura dá conta do humano. "Aumentar a consciência de incompletude cultural é uma das tarefas prévias à construção de uma concepção emancipadora e multicultural dos direitos humanos" (Santos, 2006, p. 446).

4. Nenhuma cultura é monolítica. Todas as culturas comportam versões diferentes da dignidade humana, algumas mais amplas do que outras, algumas mais abertas a outras culturas do que outras. Os grupos culturais não são homogêneos e padronizados. Algumas versões dessa cultura podem ser rígidas, estreitas e fechadas. É necessário identificar e potencializar aquelas versões mais abertas, amplas e que apresentam um círculo de reciprocidade mais amplo, que favoreçam o diálogo com outras culturas.

5. Todas as culturas tendem a distribuir as pessoas e os grupos sociais entre dois princípios competitivos de pertença hierárquica: princípio da igualdade e princípio da diferença. Esta última premissa situa-nos no âmago da questão da ressignificação dos direitos humanos hoje.

Todas essas premissas estão voltadas para essa grande questão da articulação entre igualdade e diferença, isto é, da passagem da afirmação da igualdade ou da diferença para a da igualdade na diferença. Não se trata de, para afirmar a igualdade, negar diferença, nem de uma visão diferencialista absoluta, que relativize a igualdade. A questão está em como trabalhar a igualdade na diferença, e aí é importante mencionar o que Santos (2006) chama de o novo imperativo transcultural, que no seu entender deve presidir uma articulação pós-moderna e multicultural das políticas de igualdade e diferença: "temos o direito a ser iguais, sempre que a diferença nos inferioriza; temos o direito de ser diferentes sempre que a igualdade nos descaracteriza" (idem, p. 462).

É nessa dialética entre igualdade e diferença, entre superar toda a desigualdade e, ao mesmo tempo, reconhecer as diferenças culturais, que os desafios dessa articulação se colocam. Essa perspectiva supõe discutir as diferentes concepções do multiculturalismo presentes nas sociedades contemporâneas.

\section{As diferentes abordagens do multiculturalismo}

A problemática do multiculturalismo suscita grande polêmica no momento atual. Defensores e críticos confrontam suas posições apaixonadamente.

Uma das características fundamentais das questões multiculturais é exatamente o fato de estarem atravessadas pelo acadêmico e o social, a produção de conhecimentos, a militância e as políticas públicas. Convém ter sempre presente que o multiculturalismo não nasceu nas universidades e no âmbito acadêmico em geral. São as lutas dos grupos sociais discriminados e excluídos de uma cidadania plena, os movimentos sociais, especialmente os relacionados às questões étnicas e, entre eles, de modo particularmente significativo, os relacionados às identidades negras, que constituem o locus de produção do multiculturalismo. Sua penetração na academia deuse num segundo momento e, até hoje, atrevo-me a afirmar, sua integração no mundo universitário é frágil e objeto de muitas discussões, talvez exatamente por seu caráter profundamente marcado pela intrínseca relação com a dinâmica dos movimentos sociais.

Outra dificuldade para penetrar na problemática do multiculturalismo se refere à polissemia do termo. A necessidade de adjetivá-lo evidencia essa realidade. Expressões como multiculturalismo conservador, liberal, celebratório, crítico, emancipador, revolucionário podem ser encontradas na produção sobre o tema e multiplicam-se continuamente. Certamente são inúmeras e diversificadas as concepções e vertentes multiculturais. Muitos autores, tanto de perspectiva liberal quanto de inspiração marxista, ${ }^{3}$ que levantam fortes

\footnotetext{
${ }^{3}$ Duas excelentes sínteses dessas críticas podem ser encon-
} tradas em: Santos e Nunes (2003) e em Torres (2001b). 
questionamentos teóricos e em relação ao seu papel na sociedade, não levam devidamente esse fato em consideração ou, quando o fazem, referem-se a aspectos mais superficiais, sem distinguir com maior profundidade as diferentes posições, ou fazem grandes generalizações.

Nesse sentido, considero imprescindível para avançar na reflexão que estou fazendo explicitar a concepção que privilegio ao tratar as questões suscitadas hoje pelo multiculturalismo.

Considero que um primeiro passo nessa direção é distinguir duas abordagens fundamentais: uma descritiva e outra prescritiva. A primeira afirma ser o multiculturalismo uma característica das sociedades atuais. Vivemos em sociedades multiculturais. Podemos afirmar que as configurações multiculturais dependem de cada contexto histórico, político e sociocultural. O multiculturalismo na sociedade brasileira é diferente daquele das sociedades européias ou da sociedade estadunidense. Nesse sentido, enfatizam-se a descrição e a compreensão da construção da formação multicultural de cada contexto específico. A perspectiva prescritiva entende o multiculturalismo não simplesmente como um dado da realidade mas como uma maneira de atuar, de intervir, de transformar a dinâmica social. Trata-se de um projeto, de um modo de trabalhar as relações culturais numa determinada sociedade e de conceber políticas públicas nessa direção. Uma sociedade multicultural constrói-se a partir de determinados parâmetros.

Dessa forma, é necessário distinguir as diferentes concepções que podem inspirar essa construção. Muitos têm sido os autores que têm oferecido indicações nessa linha e enumerado uma grande quantidade de tipos de abordagens multiculturais. No contexto do presente trabalho, vou-me referir unicamente a três perspectivas que considero fundamentais e que estão na base das diversas propostas: o multiculturalismo assimilacionista, o multiculturalismo diferencialista ou monoculturalismo plural e o multiculturalismo interativo, também denominado interculturalidade.

A abordagem assimilacionista parte da afirmação de que vivemos numa sociedade multicultural, no sentido descritivo. Nessa sociedade multicultural todos não têm as mesmas oportunidades; não existe igualdade de oportunidades. Há grupos, como os indígenas, negros, homossexuais, pessoas oriundas de determinadas regiões geográficas do próprio país ou de outros países e de classes populares e/ou com baixos níveis de escolarização, que não têm o mesmo acesso a determinados serviços, bens, direitos fundamentais que têm outros grupos sociais, em geral, de classe média ou alta, brancos e com altos níveis de escolarização. Uma política assimilacionista - perspectiva prescritiva - favorece que todos se integrem na sociedade e sejam incorporados à cultura hegemônica. No entanto, não se mexe na matriz da sociedade, procura-se assimilar os grupos marginalizados e discriminados aos valores, mentalidades, conhecimentos socialmente valorizados pela cultura hegemônica. No caso da educação, promove-se uma política de universalização da escolarização, todos são chamados a participar do sistema escolar, mas sem que se coloque em questão o caráter monocultural presente na sua dinâmica, tanto no que se refere aos conteúdos do currículo quanto às relações entre os diferentes atores, às estratégias utilizadas nas salas de aula, aos valores privilegiados etc. Simplesmente os que não tinham acesso a esses bens e a essas instituições são incluídos nelas tal como elas são. Essa posição defende o projeto de construir uma cultura comum e, em nome dele, deslegitima dialetos, saberes, línguas, crenças, valores "diferentes", pertencentes aos grupos subordinados, considerados inferiores explícita ou implicitamente. Segundo McLaren, "um pré-requisito para juntar-se à turma é desnudar-se, desracializar-se, e despir-se de sua própria cultura" (1997, p. 115).

Uma segunda concepção pode ser denominada multiculturalismo diferencialista ou, segundo Amartya Sen (2006), monocultura plural. Essa abordagem parte da afirmação de que, quando se enfatiza a assimilação, se termina por negar a diferença ou por silenciála. Propõe então colocar a ênfase no reconhecimento da diferença e, para garantir a expressão das diferentes identidades culturais presentes num determinado 
contexto, garantir espaços em que estas se possam expressar. Afirma-se que somente assim os diferentes grupos socioculturais poderão manter suas matrizes culturais de base. Algumas das posições nessa linha terminam por ter uma visão estática e essencialista da formação das identidades culturais. É então enfatizado o acesso a direitos sociais e econômicos e, ao mesmo tempo, é privilegiada a formação de comunidades culturais homogêneas com suas próprias organizações - bairros, escolas, igrejas, clubes, associações etc. Na prática, em muitas sociedades atuais terminou-se por favorecer a criação de verdadeiros apartheids socioculturais.

Essas duas posições são as mais desenvolvidas nas sociedades em que vivemos. Algumas vezes convivem de maneira tensa e conflitiva. São elas que, em geral, são focalizadas nas polêmicas sobre a problemática multicultural. No entanto, situo-me na terceira perspectiva, que propõe um multiculturalismo aberto e interativo, que acentua a interculturalidade, por considerá-la a mais adequada para a construção de sociedades, democráticas e inclusivas, que articulem políticas de igualdade com políticas de identidade.

\section{A perspectiva intercultural}

Algumas características especificam essa perspectiva. Uma primeira, que considero básica, é a promoção deliberada da inter-relação entre diferentes grupos culturais presentes em uma determinada sociedade. Nesse sentido, essa posição situa-se em confronto com todas as visões diferencialistas que favorecem processos radicais de afirmação de identidades culturais específicas, assim como com as perspectivas assimilacionistas que não valorizam a explicitação da riqueza das diferenças culturais.

Em contrapartida, rompe com uma visão essencialista das culturas e das identidades culturais. Concebe as culturas em contínuo processo de elaboração, de construção e reconstrução. Certamente cada cultura tem suas raízes, mas essas raízes são históricas e dinâmicas. Não fixam as pessoas em determinado padrão cultural.
Uma terceira característica está constituída pela afirmação de que nas sociedades em que vivemos os processos de hibridização cultural são intensos e mobilizadores da construção de identidades abertas, em construção permanente, o que supõe que as culturas não são puras. Sempre que a humanidade pretendeu promover a pureza cultural e étnica, as conseqüências foram trágicas: genocídio, holocausto, eliminação e negação do outro. A hibridização cultural é um elemento importante para levar em consideração na dinâmica dos diferentes grupos socioculturais.

A consciência dos mecanismos de poder que permeiam as relações culturais constitui outra característica dessa perspectiva. As relações culturais não são relações idílicas, não são relações românticas; estão construídas na história e, portanto, estão atravessadas por questões de poder, por relações fortemente hierarquizadas, marcadas pelo preconceito e pela discriminação de determinados grupos.

Uma última característica que gostaria de assinalar diz respeito ao fato de não desvincular as questões da diferença e da desigualdade presentes hoje de modo particularmente conflitivo, tanto no plano mundial quanto em cada sociedade. A perspectiva intercultural afirma essa relação, que é complexa e admite diferentes configurações em cada realidade, sem reduzir um pólo ao outro.

A abordagem intercultural que assumo aproxima-se do multiculturalismo crítico de McLaren (1997). O multiculturalismo crítico e de resistência parte da afirmação de que o multiculturalismo tem de ser situado a partir de uma agenda política de transformação, sem a qual corre o risco de se reduzir a outra forma de acomodação à ordem social vigente. Entende as representações de raça, gênero e classe como produto das lutas sociais sobre signos e significações. Privilegia a transformação das relações sociais, culturais e institucionais em que os significados são gerados. Recusa-se a ver a cultura como não-conflitiva e argumenta que a diferença deve ser afirmada "dentro de uma política de crítica e compromisso com a justiça social” (p. 123). 
A perspectiva intercultural que defendo quer promover uma educação para o reconhecimento do "outro", para o diálogo entre os diferentes grupos sociais e culturais. Uma educação para a negociação cultural, que enfrenta os conflitos provocados pela assimetria de poder entre os diferentes grupos socioculturais nas nossas sociedades e é capaz de favorecer a construção de um projeto comum, pelo qual as diferenças sejam dialeticamente integradas. A perspectiva intercultural está orientada à construção de uma sociedade democrática, plural, humana, que articule políticas de igualdade com políticas de identidade.

Para Catherine Walsh (2001, p. 10-11), a interculturalidade é

[...] um processo dinâmico e permanente de relação, comunicação e aprendizagem entre culturas em condições de respeito, legitimidade mútua, simetria e igualdade.

Um intercâmbio que se constrói entre pessoas, conhecimentos, saberes e práticas culturalmente diferentes, buscando desenvolver um novo sentido entre elas na sua diferença.

Um espaço de negociação e de tradução onde as desigualdades sociais, econômicas e políticas, e as relações e os conflitos de poder da sociedade não são mantidos ocultos e sim reconhecidos e confrontados.

Uma tarefa social e política que interpela o conjunto da sociedade, que parte de práticas e ações sociais concretas e conscientes e tenta criar modos de responsabilidade e solidariedade.

Uma meta a alcançar.

Para essa autora, apesar de vários países latinoamericanos terem introduzido a perspectiva intercultural nas reformas educativas, "não há um entendimento comum sobre as implicações pedagógicas da interculturalidade, nem até que ponto nelas se articulam as dimensões cognitiva, procedimental e atitudinal; ou o próprio, o dos outros e o social” (p. 12).

Essa autora, coordenadora do programa de doutorado em Estudos Culturais Latino-Americanos da Universidad Andina Simon Bolivar (sede Equador), vem desenvolvendo trabalhos interessantes e inovadores sobre a questão intercultural hoje na América Latina, especialmente a partir da experiência dos países andinos. Afirma que:

O conceito de interculturalidade é central à (re)construção de um pensamento crítico - outro - um pensamento crítico de/desde outro modo, precisamente por três razões principais: primeiro porque está vivido e pensado desde a experiência vivida da colonialidade [...]; segundo, porque reflete um pensamento não baseado nos legados eurocêntricos ou da modernidade e, em terceiro, porque tem sua origem no sul, dando assim uma volta à geopolítica dominante do conhecimento que tem tido seu centro no norte global. (Walsh, 2005, p. 25)

Considero importante neste momento retomar o diálogo com Boaventura Sousa Santos. Para esse autor, as premissas anteriormente enumeradas constituem a base de um diálogo intercultural, imprescindível para a ressignificação dos direitos humanos a partir das questões colocadas pelo multiculturalismo. Esse diálogo vai exigir o desenvolvimento do que ele denomina uma hermenêutica diatópica, assim concebida:

A hermenêutica diatópica baseia-se na idéia de que os topoi $i^{4}$ de uma dada cultura, por mais fortes que sejam, são tão incompletos quanto a própria cultura a que pertencem [...]. O objetivo da hermenêutica diatópica não é, porém, atingir a completude - um objetivo inatingível - mas, pelo contrário, ampliar ao máximo a consciência de incompletude mútua através de um diálogo que se desenrola, por assim dizer, com um pé numa cultura e outro noutra. Nisto reside seu caráter diatópico. (Santos, 2006, p. 448)

A luta pelos direitos humanos hoje supõe o exercício do diálogo intercultural que, por sua vez, exige

${ }^{4}$ Para Santos (2006, p. 447) “os topoi são os lugares comuns retóricos mas abrangentes de determinada cultura. Funcionam como premissas de argumentação que, por não se discutirem, dada a sua evidência, tornam possível a produção e a troca de argumentos". 
o exercício da hermenêutica diatópica. Esta constitui uma tarefa complexa e desafiante, que está dando apenas seus primeiros passos. São poucos os autores e as iniciativas que se colocam nessa perspectiva. A análise da problemática dos direitos humanos e as práticas sociais orientadas a trabalhá-las ainda estão aprisionadas na matriz da modernidade. Além disso, as concepções dominantes sobre o diálogo intercultural situam-se, em geral, numa perspectiva liberal e focalizam com freqüência as interações entre diferentes grupos socioculturais de modo superficial, sem enfrentar a temática das relações de poder que as perpassam.

\section{Interculturalidade e educação em direitos humanos: principais desafios}

Em diferentes trabalhos e pesquisas realizados nos últimos anos (Candau, 1997a, 1997b, 2000a, 2000b, 2002, 2003, 2004a, 2004b, 2005, 2006; Candau \& Moreira, 2003), tenho procurado identificar e enumerar alguns dos desafios que temos de enfrentar se quisermos promover uma educação intercultural em perspectiva crítica e emancipatória, que respeite e promova os direitos humanos e articule questões relativas à igualdade e à diferença. Eles apresentam um caráter inicial e exploratório e querem situar-se em diálogo com a proposta do professor Boaventura Sousa Santos.

Foram agrupados em torno de determinados núcleos que considero fundamentais.

$\mathrm{O}$ primeiro está relacionado à necessidade de desconstrução. Para a promoção de uma educação intercultural é necessário penetrar no universo de preconceitos e discriminações que impregna - muitas vezes com caráter difuso, fluido e sutil - todas as relações sociais que configuram os contextos em que vivemos. A "naturalização" é um componente que faz em grande parte invisível e especialmente complexa essa problemática. Promover processos de desnaturalização e explicitação da rede de estereótipos e préconceitos que povoam nossos imaginários individuais e sociais em relação aos diferentes grupos sociocul- turais é um elemento fundamental sem o qual é impossível caminhar. Outro aspecto imprescindível é questionar o caráter monocultural e o etnocentrismo que, explícita ou implicitamente, estão presentes na escola e nas políticas educativas e impregnam os currículos escolares; é perguntar-nos pelos critérios utilizados para selecionar e justificar os conteúdos escolares, é desestabilizar a pretensa "universalidade" dos conhecimentos, valores e práticas que configuram as ações educativas.

Um segundo núcleo de preocupações relacionase à articulação entre igualdade e diferença no nível das políticas educativas, assim como das práticas pedagógicas. Essa preocupação supõe o reconhecimento e a valorização das diferenças culturais, dos diversos saberes e práticas e a afirmação de sua relação com o direito à educação de todos/as. Reconstruir o que consideramos "“comum" a todos e todas, garantindo que nele os diferentes sujeitos socioculturais se reconheçam, assegurando, assim, que a igualdade se explicite nas diferenças que são assumidas como referência comum, rompendo, dessa forma, com o caráter monocultural da cultura escolar.

Quanto ao terceiro núcleo, ele vincula-se ao resgate dos processos de construção das identidades culturais, tanto no nível pessoal como coletivo. Um elemento fundamental nessa perspectiva são as histórias de vida e da construção de diferentes comunidades socioculturais. É muito importante esse resgate das histórias de vida, tanto pessoais quanto coletivas, e que elas possam ser contadas, narradas, reconhecidas, valorizadas como parte de processo educacional. Além disso, deve ser dada especial atenção aos aspectos relativos à hibridização cultural e à constituição de novas identidades culturais. É importante que se opere com um conceito dinâmico e histórico de cultura, capaz de integrar as raízes históricas e as novas configurações, evitando uma visão das culturas como universos fechados e em busca do "puro", do "autêntico" e do "genuíno", como uma essência preestabelecida e um dado que não está em contínuo movimento. Esse aspecto relaciona-se também ao reconhecimento e à promoção do diálogo entre os diferentes 
saberes, conhecimentos e práticas dos diferentes grupos culturais.

Um último núcleo tem como eixo fundamental promover experiências de interação sistemática com os "outros": para sermos capazes de relativizar nossa própria maneira de situar-nos diante do mundo e atribuir-lhe sentido, é necessário que experimentemos uma intensa interação com diferentes modos de viver e expressar-se. Não se trata de momentos pontuais, mas da capacidade de desenvolver projetos que suponham uma dinâmica sistemática de diálogo e construção conjunta entre diferentes pessoas e/ou grupos de diversas procedências sociais, étnicas, religiosas, culturais etc. Exige romper toda tendência à guetificação presente também nas instituições educativas e supõe um grande desafio para a educação. Exige também reconstruir a dinâmica educacional. A educação intercultural não pode ser reduzida a algumas situações e/ou atividades realizadas em momentos específicos nem focalizar sua atenção exclusivamente em determinados grupos sociais. Trata-se de um enfoque global que deve afetar todos os atores e todas as dimensões do processo educativo, assim como os diferentes âmbitos em que ele se desenvolve. No que diz respeito à escola, afeta a seleção curricular, a organização escolar, as linguagens, as práticas didáticas, as atividades extraclasse, o papel do/a professor/a, a relação com a comunidade etc.

Outro elemento de especial importância referese a favorecer processos de "empoderamento", principalmente orientados aos atores sociais que historicamente tiveram menos poder na sociedade, ou seja, tiveram menores possibilidades de influir nas decisões e nos processos coletivos. O "empoderamento" começa por liberar a possibilidade, o poder, a potência que cada pessoa tem para que ela possa ser sujeito de sua vida e ator social. O "empoderamento" tem também uma dimensão coletiva, trabalha com grupos sociais minoritários, discriminados, marginalizados etc., favorecendo sua organização e sua participação ativa na sociedade civil. As ações afirmativas são estratégias orientadas ao "empoderamento". Tanto as concebidas no sentido restrito quanto as que se situam num enfoque amplo, desenvolvem estratégias de fortalecimento do poder de grupos marginalizados para que estes possam lutar pela igualdade de condições de vida em sociedades marcadas por mecanismos estruturais de desigualdade e discriminação. Têm no horizonte promover transformações sociais. Nesse sentido, são necessárias para que se corrijam as marcas da discriminação construída ao longo da história. Visam melhores condições de vida para os grupos marginalizados, a superação do racismo, da discriminação de gênero, da discriminação étnica e cultural, assim como das desigualdades sociais. Outro aspecto fundamental é a formação para uma cidadania aberta e interativa, capaz de reconhecer as assimetrias de poder entre os diferentes grupos culturais e de trabalhar os conflitos e promover relações solidárias.

O desenvolvimento de uma educação intercultural na perspectiva apresentada neste texto é uma questão complexa, atravessada por tensões e desafios. Exige problematizar diferentes elementos do modo como hoje, em geral, concebemos nossas práticas educativas e sociais. As relações entre direitos humanos, diferenças culturais e educação colocam-nos no horizonte da afirmação da dignidade humana num mundo que parece não ter mais essa convicção como referência radical. Nesse sentido, trata-se de afirmar uma perspectiva alternativa e contra-hegemônica de construção social, política e educacional.

A perspectiva intercultural quer promover uma educação para o reconhecimento do outro, o diálogo entre os diferentes grupos socioculturais. Uma educação para a negociação cultural, o que supõe exercitar o que Santos denomina hermenêutica diatópica. A perspectiva intercultural está orientada à construção de uma sociedade democrática, plural, humana, que articule políticas de igualdade com políticas de identidade.

Termino com umas palavras de Boaventura Sousa Santos (2006), referidas à complexidade e às dificuldades para uma ressignificação dos direitos humanos, para uma concepção intercultural das políticas emancipatórias de direitos humanos: 
Este projeto pode parecer bastante utópico. É, certamente, tão utópico quanto o respeito universal pela dignidade humana. E nem por isso este último deixa de ser uma exigência ética séria. Como disse Sartre, antes de concretizada, uma idéia apresenta uma estranha semelhança com a utopia. Nos tempos que correm, o importante é não reduzir a realidade apenas ao que existe. (p. 470)

\section{Referências bibliográficas}

CANDAU, Vera Maria. Pluralismo cultural, cotidiano escolar e formação de professores; In: CANDAU, Vera Maria (Org.). Magistério: construção cotidiana. Rio de Janeiro: Vozes, 1997a. p. 237-250. Mudanças culturais e redefinição do escolar: tensões e buscas. Contemporaneidade e educação, Rio de Janeiro: IEC, $1997 b$.

Cotidiano escolar e cultura(s): encontros e desencontros. In: . (Org.). Reinventar a escola. Petrópolis: Vozes, 2000a. p. 61-78. Interculturalidade e educação escolar. In:

Reinventar a escola. Petrópolis: Vozes, 2000b. p. 47-60.

. (Org.). Sociedade, educação e cultura(s): questões e propostas. Petrópolis: Vozes, 2002.

. Educação intercultural no contexto brasileiro: questões e desafios. In: SEMINÁRIO INTERNACIONAL DE EDUCAÇÃO INTERCULTURAL, GÊNERO E MOVIMENTOS SOCIAIS, 2., 2000, Florianópolis. Anais.... Florianópolis: Universidade Federal de Santa Catarina, 2003. 1 CD-ROM.

Multiculturalismo e educação em direitos humanos. In: MAGDENZO, Abraham (Ed.). De miradas y mensajes a la educación en derechos humanos. Santiago: Lom, 2004a. p. 127-135.

Universidade e diversidade cultural: alguns desafios a partir da experiência da PUC-Rio. In: PAIVA, Angela (Org.). Ação afirmativa na universidade: reflexão sobre experiências concretas Brasil-Estados Unidos. Rio de Janeiro: Ed. PUC-Rio/ Desiderata, 2004b. p. 87-108.

(Org.). Cultura(s) e educação: entre o crítico e o pós-crítico. Rio de Janeiro: DP\&A, 2005.

(Org.). Educação intercultural e cotidiano escolar. Rio de Janeiro: 7 Letras, 2006.

.; MOREIRA, Antônio Flávio. Educação escolar e cultura(s): construindo caminhos. Revista Brasileira de Educação, n. 23, p. 156-168, maio/ago. 2003.
GIMENO SACRISTÁN, José. Políticas de la diversidad para una educación democrática igualadora. In: SIPÁN COMPAÑE, Antonio (Coord.). Educar para la diversidad en el siglo XXI. Zaragoza: Mira, 2001. p. 123-142.

McLAREN, Peter. Multiculturalismo crítico. Trad. Bebel Orofino Shaefer. São Paulo: Cortez, 1997.

ORTIZ, Renato. Mundialização e cultura. São Paulo: Brasiliense, 1994.

PIERUCCI, Antonio Flavio. Ciladas da diferença. São Paulo: Editora 34, 1999.

PNUD - Programa das Nações Unidas para o Desenvolvimento. Relatório do desenvolvimento humano 2004: liberdade cultural num mundo diversificado. Lisboa: Mensagem, 2004.

SANTOS, Boaventura de Sousa (Org.). Reconhecer para libertar: os caminhos do cosmopolitismo multicultural. Rio de Janeiro: Civilização Brasileira, 2003.

- A gramática do tempo: para uma nova cultura política. São Paulo: Cortez, 2006.

.; NUNES, João Arriscado. Introdução: para ampliar o cânone do reconhecimento, da diferença e da igualdade. In: SANTOS, B. de S. (Org.). Reconhecer para libertar: os caminhos do cosmopolitismo multicultural. Rio de Janeiro: Civilização Brasileira, 2003, p. 25-26.

SEN, Amartya. O racha do multiculturalismo. Folha de S.Paulo, São Paulo, Suplemento Mais, p. 8, 17 set. 2006.

TORRES, Carlos Alberto. Democracia, educação e multiculturalismo. Petrópolis: Vozes, 2001a.

. Multiculturalismo. In: Democracia, educação e multiculturalismo. Petrópolis: Vozes, 2001b.

WALSH, Catherine. La educación intercultural en la educación. Peru: Ministerio de Educación, 2001. Mimeografado.

(Ed.). Pensamiento crítico y matriz (de)colonial; reflexiones latinoamericanas. Quito: Universidad Andina Simon Bolivar/Abya-Yala, 2005.

VERA MARIA FERRÃO CANDAU realizou estudos de pós-graduação em pedagogia e filosofia na Universidade Católica de Louvain (Bélgica) e o doutorado e o pós-doutorado na Universidad Complutense de Madrid (Espanha). É atualmente professora titular do Departamento de Educação da Pontifícia Universidade Católica do Rio de Janeiro (PUC-RJ), membro do Comitê Nacional de Educação em Direitos Humanos e consultora de diferentes órgãos de fomento à pesquisa e à pós-graduação. 
Principais publicações: Magistério: construção cotidiana (Rio de Janeiro: Vozes, 1997); Reinventar a escola (Rio de Janeiro: Vozes, 2000); Educar em direitos humanos, construir cidadania (Rio de Janeiro: DP\&A, 2000); Escola e violência (Rio de Janeiro: DP\&A, 2001); Sociedade, educação e cultura(s) (Rio de Janeiro: Vozes, 2002); Discriminación, sociedad y escuela en America Latina (Bolivia: Runa, 2002); Cultura(s) e educação (Rio de Janeiro: DP\&A, 2005); Educação intercultural e cotidiano escolar (Rio de Janeiro: 7 Letras, 2006). Coordena, desde 1996, o Grupo de Estudos sobre Cotidiano, Educação e Cultura(s) (GECEC), no qual está desenvolvendo, desde 2006, com auxílio do Conselho Nacional de Desenvolvimento Científico e Tecnológico (CNPq), a pesquisa "Multiculturalismo, direitos humanos e educação: a tensão entre igualdade e diferença". E-mail: vmfc@edu.puc-rio.br

Recebido em setembro de 2007 Aprovado em novembro de 2007 
Vera Maria Candau

Direitos humanos, educação e interculturalidade: as tensões entre igualdade e diferença

$\mathrm{O}$ artigo apresenta algumas questões relativas à importância da(s) cultura(s) no momento atual. Discute a relevância do discurso dos direitos humanos nesse contexto, tendo como principal interlocutor o sociólogo Boaventura Sousa Santos. Analisa diferentes abordagens do multiculturalismo. Assume a perspectiva intercultural, justificando sua relevância. Assinala alguns desafios que considera de especial importância para trabalhar as relações entre educação intercultural e direitos humanos.

Palavras-chave: direitos humanos; multiculturalismo; educação intercultural; igualdade; diferença

\section{Human rights, education and} interculturality: tensions between equality and difference

This article presents some questions related to the importance of culture in the present moment. It discusses the relevance of the human rights discourse within this context, taking as its main interlocutor the sociologist Boaventura Sousa Santos. It analyses different approaches to multiculturalism. It justifies the relevance of the intercultural perspective adopted and points to challenges considered to be of particular importance for developing the relationships between intercultural education and human rights.
Key words: human rights; multiculturalism; intercultural education; equality; difference

Derechos humanos, educación e interculturalidad: las tensiones entre igualdad y diferencia

Este artículo presenta algunas cuestiones relativas a la problemática de la(s) cultura(s) en el momento actual. Discute la relevancia del discurso de los derechos humanos en este contexto, teniendo como interlocutor al sociólogo Boaventura Sousa Santos. Analiza distintos enfoques del multiculturalismo. Asume la perspectiva intercultural y justifica esta opción. Señala algunos desafios que considera importantes para que se trabajen en las relaciones entre educación intercultural y derechos humanos.

Palabras claves: derechos humanos; multiculturalismo; educación intercultural; igualdad; diferencia 